\title{
Article
}

\section{A systematic review of sport-based life skills programs for young people: The quality of design and evaluation methods}

Williams, Charlotte, Neil, Rich, Cropley, Brendan, Woodman, Tim and Roberts, Ross

Available at http://clok.uclan.ac.uk/35310/

Williams, Charlotte ORCID: 0000-0002-2665-7823, Neil, Rich, Cropley, Brendan, Woodman, Tim and Roberts, Ross (2020) A systematic review of sport-based life skills programs for young people: The quality of design and evaluation methods. Journal of Applied Sport Psychology, 2020 . p. 1. ISSN $1041-3200$

It is advisable to refer to the publisher's version if you intend to cite from the work. http://dx.doi.org/10.1080/10413200.2020.1792583

For more information about UCLan's research in this area go to

http://www.uclan.ac.uk/researchgroups/ and search for <name of research Group>.

For information about Research generally at UCLan please go to http://www.uclan.ac.uk/research/

All outputs in CLoK are protected by Intellectual Property Rights law, including Copyright law. Copyright, IPR and Moral Rights for the works on this site are retained by the individual authors and/or other copyright owners. Terms and conditions for use of this material are defined in the policies page. 
1 A systematic review of sport-based life skills programs for young people: The quality of design and evaluation methods

5 Authors: Charlotte Williams ${ }^{1}$, Rich Neil*1, Brendan Cropley ${ }^{2}$, Tim Woodman ${ }^{3}$, Ross Roberts ${ }^{3}$. 6

${ }^{1}$ Cardiff School of Sport and Health Sciences, Cardiff Metropolitan University

$8 \quad{ }^{2}$ School of Health, Sport and Professional Practice, University of South Wales

$9 \quad{ }^{3}$ School of Sport, Health and Exercise Sciences, Bangor University

* Corresponding Author: Contact - $\underline{\text { rneil @ cardiffmet.ac.uk }}$

13

14 


\section{Abstract}

35 Over the past two decades, researchers have reported positive life skills outcomes for young people

36 participating in sport-based life-skills programs. However, to date, there has been a lack of

37 consideration in the literature regarding the quality of the programs designed and the evaluation

38 methods adopted. Therefore, we conducted a systematic review of the life skills literature to: (a) assess

39 the quality of sport-based life skills program design and evaluation methods; and (b) identify

40 characteristics relating to the quality of sport-based life skills programs where authors had evidenced

41 life skills development and transfer. Using the PRISMA guidelines, we searched six databases for

42 relevant research papers and applied inclusion and exclusion criteria to the papers returned, of which 13

43 papers met the criteria. We conducted two quality assessment exercises (design and evaluation

44 methods) and found two moderate-high quality life skills programs, ten moderate quality programs, and

45 one low quality program. We present the characteristics (regarding quality) of intervention designs and

46 methods, conclude with recommendations for designing quality sport-based life skills programs, and

47 provide guidelines for researchers to evaluate sport-based life skills programs.

48 Lay Summary: Through engaging in sport-based life skills programs, young people can develop

49 transferable skills. However, the quality of these life skills programs is unclear. We assess the quality of

50 the design and evaluation methods of sport-based life skills programs, present the characteristics of

51 moderate-high and moderate quality programs, and offer recommendations for future research and

52 practice.

53 Practical Implications:

54 - The characteristics identified can be used to aid the development of the content, delivery and

55 evaluation methods within future sport-based life skills programs.

56 - The quality assessment tool (QATID) that is embedded within this paper can be used by

57 applied researchers to ensure that the design of their life skills interventions is of high quality.

58 - By using the QATID and the Mixed Method Appraisal Tool (MMAT) when designing and

59 evaluating sport-based life skills programs, applied researchers can validate better subsequent

$60 \quad$ claims of program effectiveness. 
A Systematic Review of Sport-based Life Skills Programs for Young People: The Quality

of Design and Evaluation Methods

Sport is a context in which young people can learn to develop functional skills that could be used in most aspects of life (Fraser-Thomas \& Côté, 2009). These functional skills are often referred to by researchers in the field of Sport Psychology as life skills, and can be categorized as behavioral, cognitive, interpersonal, or intrapersonal skills (Danish, Forneris,

67 Hodge, and Heke, 2004). Over the past three decades numerous researchers have developed, 68 implemented, and evaluated programs within sport and physical activity contexts to promote 69 the development of life skills in young people (under the age of 18). Indeed, programs such as 70 Going for Goal (GOAL; Danish, 1992), Sports United to Promote Education and Research (SUPER; Danish, 2002), and The First Tee (Weiss, Stuntz, Bhalla, Bolter, \& Price, 2013) have been used as mechanisms to evidence the positive relationship between sport participation and

73 life skills development (e.g., Bean, Kendellen, \& Forneris, 2016; Papacharisis, Goudas,

74 Danish, \& Theodorakis, 2005; Weiss et al., 2013). As a result of taking part in these life skills programs, researchers have proposed that young people can develop skills such as goal setting, emotional regulation, and communication.

Whilst young people appear to glean life skills via participation in sport, the pathway via which they do so remains unclear. To this end, Mahoney, Eccles, and Larson (2004) proposed that the structure and delivery of youth-based activities can determine whether young people experience positive or negative outcomes. Specifically, Mahoney (2000) noted that intentionally structured programs with clear program outcomes tend to lead to more favourable developmental results than non-structured programs. Advancing this perspective, researchers introduced the notion of implicit and explicit life skills development and transfer (Bean,

84 Kramers, Forneris, \& Camiré, 2018; Turnnidge, Côté, \& Hancock, 2014). Specifically, an implicit approach denotes the conditions coaches put in place to facilitate life skills 
development or transfer (Turnnidge et al., 2014). In comparison, an explicit approach consists of those delivering life skills programs drawing upon specific pedagogical strategies to facilitate life skills development and transfer.

$$
\text { Researchers have claimed 'effectiveness' of these life skills programs through }
$$

illustrating that participants developed and/or transferred (to a different context from sport) life skills. Each of these programs varies in relation to the design and evaluation methods adopted by researchers. Due to the variations across programs, it is often difficult to synthesize knowledge and, thus, compare life skills programs (Hodge, Danish, \& Martin, 2012). In the broader field of positive youth development, researchers have attempted to synthesise knowledge through publishing an array of critical reviews. These include: a qualitative metastudy of positive youth development through sport (Holt et al., 2017); a systematic review on the impact of sport on the positive youth development of high performance athletes (Rigoni, Beleem, \& Vieira, 2017); an integrative review of sport-based youth development literature (Jones, Edwards, Bocarro, Bunds, \& Smith, 2017); a systematic review of life skills devlopment through sports programs serving socially vulnerable youth (Hermens, Super, Verkooijen, \& Koelen, 2017); a systematic review of sport-based youth development programs in the United States (Whitley, Massey, Camiré, Boutet, \& Borbee, 2019a); and a systematic review of sport for development interventions across six cities (Whitley et al., 2019b). Each of these reviews has enhanced our knowledge and understanding of positive youth development within a sport context. However, an important stage within a systematic review is establishing the quality of the papers included within the review and the quality of methods adopted by the reviewer. In doing so, this helps to increase a reader's level of confidence in the results presented by the researchers who conducted the systematic review, and minimises risk of bias. In reviewing the quality of the design of youth development programs and/or the quality of evaluation methods adopted, those conducting systematic reviews can assess the strength of researchers' claims of intervention effectiveness. That is, through assessing quality we can start 
113 to identify if the outcomes presented by researchers can be believed (Higgins, 2008). Whilst

114 evaluating the quality of papers within a review has been noted as an integral stage within the

115 systematic review process, few researchers in the domains of life skills development through

116 sport and positive youth development have focused their reviews entirely on assessing quality.

117 Rather, researchers have attempted to assess quality as a secondary aim within their review

118 (e.g., Holt et al., 2017) or have assessed the quality of papers as a means to determine which

119 papers to include/exclude within their review (e.g., Hermans et al., 2017). Indeed, only two

120 groups of authors have focused their review primarily on assessing the methodological quality

121 of youth development programs (e.g., Whitley et al., 2019a; 2019b). As such, only two of the

122 above review papers examined methodological quality in sufficient breadth and depth.

In 2017, both Holt and colleagues, and Hermans and colleagues attempted to assess the

124 methodological quality of the papers included within their review. To assess quality, Holt et al.

125 conducted a meta-method analysis whereby they appraised the strengths and weaknesses of the

126 methods employed by researchers. From this, Holt et al. concluded that the strengths of the

127 studies were attributable to "multiple data collection and validity techniques, which facilitated

128 the production of high-quality data" (Holt et al., 2017, p. 38). Whilst Holt et al. have attempted

129 to explore quality, the main purpose of their review was not to evaluate quality; rather, their

130 focus was on creating a model of positive youth development. Additionally, they drew

131 conclusions relating to 'high-quality data' without engaging in a formal analysis of 'quality'.

132 Indeed, their conclusions are based on two aspects of methodological quality (i.e., data

133 collection methods and validation techniques, such as member checking). As such, it is

134 important for researchers to adopt explicit, validated strategies to assess a broad and

135 comprehensive range of methodological quality indicators in order to make valid claims in

136 relation to the quality of studies. It is important to note, that Holt et al. (2017) may not have

137 disclosed the specific protocols followed to evauate quality due to publication restrictions (e.g.,

138 an 8000 word limit). 
Hermens et al. (2017) adopted a different approach to assessing quality by evaluating

140 the 'rigour' of studies using the results as an inclusion criteria for their review. Specifically,

141 they utilised the TAPUPAS (Transparance, Accuracy, Purposivity, Utility, Propriety,

142 Accessibility, Specificity) framework (Pawson, Boaz, Grayson, Long, \& Barnes, 2003) and

143 postulated that only papers with medium, or high rigour would be included within their review.

144 In adopting this approach, Hermens et al. made attempts to infer that the results of the papers

145 included within the review were valid. Recently, Whitley and colleagues (2019a; 2019b)

146 conducted two reviews of sport-based youth development programs and explicitly focused on

147 assessing the methodological quality of research. Specifically, Whitley et al. (2019a)

148 conducted a review of sport-based youth development programs, assessing the methodological

149 quality of evaluations of sport-based youth development programs in the USA, with the aim of

150 identifying characteristis of intervention efficacy. Their results, in relation to quality, reflected

151 "weak" and "incoherent" interventions. Due to the low quality of interventions, they were

152 unable to identify the characteristics of effective programs. Consequently, whilst researchers

153 have claimed that sport-based youth programs can enhance the development of life skills, the

154 quality of the evaluation methods used by researchers to evaluate the programs is weak. Whilst

155 Whitley and colleagues (2019a; 2019b) enhanced our understanding of quality and the

156 relationship between methodological quality and youth development program outcomes, they

157 did not consider the quality of the design of such programs. A lack of consideration for the

158 quality of program design is also evident within the broader context of the youth development

159 literature. Indeed, there has been no focus on whether the design of life skills interventions are

160 of high quality. Thus, researchers' reports of intervention effectiveness is questionable.

161 Therefore, it is imperative to explore the quality of design and the quality of evaluations of

162 sport-based life skills programs.

163 Purpose and Aim 
Given the aforementioned variations across studies, and the lack of research assessing both the evaluative and design quality of life skills interventions, we sought to conduct a systematic review. Through adopting a systematic process of identifying, appraising, and synthesizing the results of all relevant individual research papers, we can begin to determine the quality of sport-based life skills interventions. Through conducting the systematic review, we, therefore, aimed to assess the quality of design and evaluation methods of sport-based life skills programs. By assessing the quality of existing life skills research, we hope to encourage researchers and practitioners to consider and/or improve the quality of life skills program

172 design, and the methodological quality of the evaluations they conduct. In doing so, they may

173 be able to evidence more reliably that life skills were developed and transferred (Higgins \&

174 Green, 2011). As a result of conducting a systematic review, we may also uncover areas where 175 knowledge may be limited (Higgins \& Green, 2011).

\section{Method}

\section{Definitions}

For the purpose of this paper, we are concerned with reviewing sport-based life skills

179 programs as opposed to life skills development efforts within traditional youth sport

180 programming. The distinguishing feature of sport-based life skills programs being that sport-

181 based life skills programs have been developed by researchers and/or practitioners to explicitly

182 focus on facilitating the development of life skills in young people through sport.

In order to conduct the review, it was important to define life skills. Currently, within

184 the sport psychology domain, a number of definitions exist that have been developed to

185 describe the term life skills. For example, Danish et al. (2004) defined life skills as, "Skills that

186 enable individulas to suceed in the different environments in which they live, such as school,

187 home, and in their neighborhoods" (p. 40). Further, Danish et al. (2004) considered life skills

188 as behavioral (e.g., communicating effectively with peers/adults) or cognitive (e.g., making

189 effective decisions), and interpersonal (e.g., being assertive), or intrapersonal (e.g., setting 
190 goals) in nature. Building on this definition, Gould and Carson (2008) proposed that life skills

191 are, “Those internal personal assets, charactersitics and skills such as goal setting, emotional

192 control, self-esteem, and hard work ethic that can be facilitated or developed in sport and are

193 transferred for us in non-sport settings" (p. 60). Whilst the definitions offered by Danish,

194 Gould and associates provided a foundation for life skills research, no acknowledgement of the

195 life skills transfer process was included within their work. Consequently, we provide our own

196 definition of life skills to guide this review:

197 "[life skills] are functional skills that individuals develop and use effectively

198 in one context to manage demands (such as the home, school, sport,

199 community, workplace) and that are also used effectively in other contexts

200 beyond that in which they were learnt."

201 Search Strategy

202 Prior to developing the search strategy, we consulted with the lead author's institution

203 librarian who supported the identification of the databases listed below and the development of

204 the search terms used within this review. We employed an electronic search strategy for

205 published studies using the following databases: (i) EBSCOhost; (ii) SPORTDiscus; (iii)

206 Education Research Complete; (iv) PsycInfo; (v) PsychArticles; and (vi) Psych Source. We

207 chose these databases as they were deemed the most suitable databases for the topic and would

208 ensure that all relevant studies were detected. Keyword combinations used in the search

209 strategies included the following Boolean search terms: Life skills OR Life skills Development

210 OR Life skills Intervention OR Life skills Program OR (Positive Youth Dev* OR PYD) AND

211 Sport $O R$ Physical activ*. Further, we also searched these databases for known authors in the

212 field (e.g., Danish). We also conducted a hand search of available literature to ensure that

213 eligible papers were not missed. To action this, we scanned the reference pages of all of the

214 included papers and published review papers in the field of life skills development through

215 sport (e.g., Gould \& Carson, 2008; Holt et al., 2017) for further relevant research articles. 


\section{Eligibility Criteria}

The criteria for inclusion in the systematic review were: (1) peer-reviewed journal

218 articles; (2) articles published in English between 1985 to the last search conducted in

219 November 2019; (3) young people under the age of 18 years old were reported as participants;

220 (4) sport-based life skills programs were the primary interventions reported. That is, sport

221 programs that were developed to specifically facilitate life skills development and/or transfer;

222 (5) life skills development and/or transfer was identified as the primary aim of the program;

223 and (6) life skills outcomes were assessed or described. That is, there was evidence (qualitative

224 or quantitative) of participants developing and/or transferring life skills.

We applied the following exclusion criteria: (1) adults over the age of 18 years old were reported as participants; (2) abstracts, book chapters, conference proceedings, dissertation

227 abstracts, editorials, forewords, or review papers; (3) articles with life skills in the title, but

228 where no reference to life skills is provided in the full body of text; (4) sport-based programs

229 where the main aim was to develop outcomes such as well-being, academic improvement, or

230 drug prevention; (5) programs that solely claim implicit development of life skills; and (6) life

231 skills outcomes were not assessed or described (i.e., there was no qualitative or quantitative

232 evidence of participants of developing and/or transferring life skills).

233 Procedure

Systematic review team. Our review team consisted of the lead author, and the second and third authors. At each stage of the process (search, screening, and data analysis), we met to discuss and challenge key decisions. In total, we met four times, with the lead and second

237 author meeting a further four times.

Search and reporting process. Initial team discussions centered around the inclusion

239 of individual life skills, such as (but not limited to) 'team work' and 'communication'. Due to

240 the vast array of individual life skills that there could potentially be, we (the review team)

241 decided to use the search term 'life skills' as an umbrella term to encapsulate all potential life 
242 skills. The lead author conducted the electronic search exercise. Following this, all returned

243 articles were stored in an electronic folder in Mendeley, a reference management tool. Manual

244 search procedures were also conducted whereby the lead author searched peer-reviewed

245 journals and the reference lists of life skills review papers.

We followed the guidelines provided within the 27-item Preferred Reporting Items for

247 Systematic Reviews and Meta-Analyses (PRISMA) to conduct the systematic review and

248 report the findings of the review (Moher, Liberati, Tetzlaff, \& Altman, 2009). In line with the

249 PRISMA guidelines, the lead author identified the studies and removed all duplicate papers.

250 Following this, the lead author screened all titles and abstracts. During the screening process,

251 discussions between the lead and second author took place, and centered on issues with one

252 particular criterion, that 'life skills are the main aim of the program'. Specifically, within some

253 papers we found it difficult to decipher the primary aim of the research. As a result of these

254 discussions, we (lead and second author) agreed to advance any ambiguous papers to the full

255 text stage. At full text stage we made the decision to remove any papers in which life skills

256 development as the primary aim could not be identified, and where it was unclear if life skills

257 outcomes were assessed or described. At this stage, the lead author applied the inclusion and

258 exclusion criteria to full texts $(n=79)$ to assess each paper's eligibility for inclusion. The lead

259 author then presented the eligibility of each of the full texts $(n=79)$ to the second and third

260 authors. Here, we discussed all papers and their eligibility for inclusion. It was at this point that

261 we reached consensus, which resulted in the inclusion of 15 papers (see Figure 1).

Quality assessment. We conducted two quality assessment exercises: (a) to assess the

263 quality of the design of each life skills program; and (b) to assess the quality of the evaluation

264 methods adopted by each research team.

Design Quality. Despite the existence of a body of research devoted to enhancing

266 program evaluation (cf. Wholey, Hatry, \& Newcomer, 2010), there appears to be no formal

267 assessment tool that can be used to assess the quality of an intervention design. Therefore, we 
268 used two existing quality assessment guides: The Consolidated Standards of Reporting Trials

269 (CONSORT) statement (Schulz, Altman, \& Moher, 2010) and The QualSyst (Kmet, Lee, \&

270 Cook, 2004) to develop our criteria for intervention design quality. These tools were developed

271 by researchers predominantly to assess the methodological quality of interventions. However,

272 the authors of the protocols identified the following indicators of good intervention design:

273 theoretical underpinning - intervention designs are informed by theory; intervention

274 description - interventions are described clearly and in depth; duration of intervention -

275 intervention duration is justified and appropriate for behavior change to occur; and,

276 implementation fidelity - the intervention is delivered as intended. These indicators have also

277 been identified as appropriate markers of intervention design quality by other authors (e.g.,

278 Davies, Walker, \& Grimshaw, 2010; Jackson \& Waters, 2005). We also searched the wider

279 literature base (i.e., sport \& exercise psychology, health, health psychology, and education

280 journals) and found that some researchers had identified other criteria to assess intervention

281 design quality. These included: individualization within program - the intervention is bespoke

282 for each participant's needs; ongoing feedback - each participant receives ongoing and tailored

283 feedback; intervention piloted - the intervention is piloted, reflected upon and, where required,

284 revised; and intervention directed at intended outcomes (intervention focus) - the intervention

285 is designed to improve the variables measured (Mullen, Green, \& Persinger, 1985).

286 Collectively, these indicators formed the criteria for our quality assessment tool for

287 intervention designs (QATID): (a) theoretically underpinned; (b) intervention description; (c)

288 duration of intervention; (d) implementation fidelity; (e) individualization within program; (f)

289 ongoing feedback; (g) pilot intervention; and (h) intervention focus. The QATID was

290 developed specifically for use within this study, however, there is potential for the QATID to

291 be used on a wider scale to evaluate the quality of intervention designs.

As a review team, we reviewed existing quality assessment scoring systems and

293 calibrated scoring system according to the question, "Does the intervention adhere to the 
294 specific quality criteria?" (Yes $=2$, Partial = 1, No = 0; Kmet et al., 2004). To reduce bias, and

295 increase the reliability of the quality assessment, the lead author independently assessed each

296 paper $(n=15)$ against the quality of intervention design criteria, and the second author

297 followed the same process for all papers $(n=15)$. Mutual agreement was made between the

298 two reviewers. We recorded $93 \%$ agreement prior to discussion, and $100 \%$ post discussion.

299 Discussions here centered on determining the classification of a life skills theory (e.g.,

300 BNT/LDI, Hodge et al., 2012) and a framework or model (e.g., Positive Youth Development;

301 Petitpas, Cornelius, Van Raalte, \& Jones, 2005). We assigned papers that used a life skills

302 theory to underpin the program with a score of 2 as a theory can be used to explain

303 relationships, and we assigned papers that incorporated a life skills framework or model with a

304 score of 1 , as these are used to describe relationships. Once we had rated each criterion, we

305 attributed an overall score to each paper. Quartile cut-off points have been used by researchers

306 to categorize levels of quality (e.g., Robertson et al., 2018). Thus, we used the following cut-

307 off points to categorize levels of quality: overall scores from 13 to 16 were high quality, overall

308 scores of 9-12 were moderate-high quality, overall scores of 5-8 were moderate quality, and

309 overall scores of 1-4 were low quality.

310 Evaluation Quality. To assess the methods adopted by researchers to evaluate life

311 skills programs within each study, we used the Mixed Methods Appraisal Tool (MMAT; Pluye

312 et al., 2011). As the researchers of the included studies used a variety of evaluation methods,

313 we determined that the MMAT was the most appropriate quality assessment tool to use. The

314 MMAT was designed to evaluate the methodological quality for three domains of research: (1)

315 qualitative research; (2) quantitative research (divided into three sub-domains; descriptive,

316 randomized control, and non-randomized control); and (3) mixed-methods research. The

317 qualitative criteria outlined in the MMAT includes: appropriateness of sampling procedure;

318 appropriateness of data analysis processes; consideration of context on data collection

319 procedures; and consideration of researchers' philosophy (i.e., ontological and epistemological 
320 beliefs). The quantitative descriptive criteria consisted of: relevance of sampling strategy;

321 appropriate representation of sample; appropriateness of measures; and acceptable response

322 rate. Finally, the quantitative non-randomized criteria within the MMAT includes:

323 minimization of selection bias; appropriateness of measures; comparable groups; and

324 acceptable response rate (for specific criterion requirements see Mixed Methods Appraisal

325 Tool guidelines; Pluye et al., 2011).

326 Each quality indicator is rated on a categorical scale (yes, no, and cannot tell), and the

327 number of yes answers are added together to create an overall score. The overall score

328 (reflected as an overall percentage) was calculated by adding the total number of 'yes' items,

329 dividing this by four, and multiplying this by 100 . So, if two out of four were scored as 'yes'

330 we divided two by four, which gave 0.5 and multiplied this by 100 to get the percentage of

$33150 \%$. Therefore, scores varied from $25 \%$ (one criteria met) to $100 \%$ (all four criteria met). In

332 line with Robertson et al. (2018), we categorized papers with overall scores of $100 \%$ as high

333 quality, overall scores of $75 \%$ as moderate-high quality, overall scores of $50 \%$ as moderate

334 quality and, overall scores of $25 \%$ as low quality. When testing the reliability and efficiency of

335 MMAT, researchers have reported that the consistency of the global score between reviewers

336 (ICC) is between 0.72 and 0.94 (Pace et al., 2012). In line with the design quality assessment

337 exercise, the lead author independently assessed each paper $(n=15)$ against the MMAT, and

338 the second author followed the same process for all papers $(n=15)$. We recorded an agreement

339 score of $87 \%$ agreement prior to discussion, and $100 \%$ post-discussion. Discussions centered

340 on the ambiguity of information (e.g., there were times when we assumed information within

341 the paper). Thus, we agreed to score the paper only if the information was present.

342 Overall Quality. To determine the overall quality of each paper, we converted the

343 QATID scores into percentages so that they were in line with the MMAT scores. We took the

344 total number scores, divided it by 16 (the total score available) and then multiplied this by 100 .

345 We then calculated the mean percentage for the two quality scores for each paper (see Table 4). 
Data extraction and synthesis. After determining scores for each paper for the quality

of design and evaluation, we (the first and second authors) used the quality criteria from both

348 assessment tools to inform the development of a paper-based data extraction form. The data

349 extraction form included generic information such as the author(s) and year of publication. In

350 addition, the data extraction form included the following information relating to the quality

351 criteria derived from the QATID: theoretical underpinning; intervention focus (i.e., clear

352 program goals, clear session descriptions, life skills embedded into program content and

353 delivery); program description (i.e., context, location, structure, life skills); duration;

354 individualization; ongoing feedback (i.e., strategies used); pilot implementation; and program

355 fidelity. Further, the data extraction form also included the following information from the

356 MMAT with regards to the quality of program evaluation: sampling procedure (i.e., sample

357 size; participant demographics); data analysis process (i.e., domain; qualitative/quantitative,

358 methods, frequency of evaluation); measures (i.e., type of measure, validity of measure);

359 comparable groups (i.e., control group); and researcher philosophy. In the following section,

360 we present the data extracted through descriptive narrative.

\section{Results}

\section{Quality Assessment Result}

We assessed 15 studies against the QATID, a total score of 16 represented the highest

364 score that any paper could achieve. Scores ranged from 3 to 10, with Huysmans, Clement,

365 Whitley, Gonzalez, and Sheehy (2019) the only one to achieve a score of 10 (see Table 1).

Of the 15 studies we assessed against the MMAT (Pluye et al., 2011), eight were

367 assessed against the qualitative criteria, four studies against the quantitative non-randomized

368 criteria, one study against the quantitative descriptive criteria, and two against the mixed

369 method criteria (see Table 2). For the eight qualitative studies, overall scores ranged between

$37025 \%-100 \%$ with three studies scoring above 50\% (i.e., Bean et al., 2016; Holt et al., 2013; 
371 Jacobs \& Wright, 2019). The quantitative non-randomized studies and the quantitative 372 descriptive scores were all 50\%. The scores for mixed method studies were $50 \%$ (see Table 2).

We combined the results from both of the quality assessment exercises (see Table 2)

374 and categorized papers into the following quartiles: high, moderate-high, moderate, or low

375 quality (Robertson et al., 2018). We categorized three papers as moderate-high quality (62.5\%-

$37675 \%), 11$ papers as moderate quality (34.5\%-56.5\%), and one paper as low quality (28\%).

377 Furthermore, in line with our working definition of life skills whereby transfer is highlighted as

378 a crucial aspect within the life skills domain, we have provided overall quality scores for the

379 papers in which life skills development and transfer is evidenced (see Tables 2 and 4). These

380 included the three papers identified as moderate-high quality (i.e., Bean et al., 2016; Huysmans

381 et al., 2019; Jacobs \& Wright, 2019); six of the 11 papers identified as moderate quality (i.e.,

382 Goudas \& Giannoudis, 2010; Hodge Kanters, Forneris, Bocarro, \& Sayre-McCord, 2017; Holt

383 et al., 2013; Waldron, 2009; Weiss et al., 2013; Weiss, Bolter, \& Kipp, 2016); and the one

384 paper identified as low quality (i.e., Lee, Park, Jang, \& Park, 2017).

\section{Summary of Studies}

In this section, we provide a descriptive overview of the design and evaluation quality characteristics that we obtained through the data extraction process. Split into two sections, we first provide an overview of the quality of the design of sport-based life skills programs and 389 then we offer insight into the quality of evaluation of sport-based life skills programs. Each 390 section is split further into sub-sections that illustrate the characteristics of either the design or 391 evaluation of life skills programs. Within each sub-section, we first provide an overview for all 392 of the papers that met the inclusion criteria $(n=15)$. Then, and in coherence with our working 393 definition that highlights transfer as an important factor within the life skills domain, we 394 illustrate the design and evaluation quality characteristics in relation to only the three 395 moderate-high and six moderate papers $(n=9)$ that we identified in the previous section, in which the authors evidenced life skills development and transfer (see Table 3 \& Table 4). 


\section{Quality of the design of sport-based life skills programs.}

Underpinned by theory. We extracted data in relation to the theoretical underpinning

399 of the programs. Of the 15 papers included within this review, the authors of only five papers

400 referred to the program being underpinned by a 'theoretical' youth development framework.

401 The authors of the remaining ten papers did not make reference to the program being

402 underpinned by any theoretical framework. Of the nine moderate-high and moderate quality

403 papers in which the authors evidenced life skills development and transfer, two group of

404 authors made reference to using Hellison's (1995) Teaching Personal and Social Responsibility

405 framework (TPSR; Bean et al., 2016; Huysmans et al., 2019) and two groups of authors made

406 reference to using Petitpas et al.’s (2005) Positive Youth Development framework as an

407 underpinning theoretical approach (Weiss et al., 2013; Weiss et al., 2016). The authors of the

408 remaining five moderate and moderate-high quality papers in which the authors evidenced life

409 skills development and transfer did not report a theoretical underpinning.

410 Intentional focus. The authors of each of the 15 papers included within this review

411 demonstrated an intentional focus on life skills development and/or transfer. We refer to

412 intentional focus as the designing of life skills programs to promote life skills development.

413 We identified three factors that contribute toward program focus: clear program goals; clear

414 session descriptions; and life skills embedded into the program content and delivery. Authors

415 of the nine moderate-high and moderate quality papers who evidenced life skills development

416 and transfer provided clear program goals, and embedded life skills into their program.

417 However, four of these authors also provided clear session descriptions that would permit a

418 practitioner to replicate the intervention (Bean et al., 2016; Goudas \& Giannoudis, 2010;

419 Hodge et al., 2017; Huysmans et al., 2019).

420 Program description. We identified that there were a range of sport-based life skills

421 programs that have been developed, implemented, and evaluated in different parts of the world:

422 Canada (3); Eswatini (1); Greece (4); Korea (1); and, USA (6). Of the nine moderate-high and 
423 moderate quality papers in which the authors evidenced life skills development and transfer,

424 five originated from the USA (Hodge et al., 2017; Jacobs \& Wright, 2019; Waldron, 2009;

425 Weiss et al., 2013; Weiss et al., 2016); two originated from Canada (Bean et al., 2016; Holt et

426 al., 2013); one originated from Greece (Goudas \& Giannoudis, 2010); and one originated from

427 Eswatini (Huysmans et al., 2019). Overall, the 15 programs were delivered across two

428 contexts, Education (9) and within the Community (6). The education context consisted of

429 physical education (3) and extra-curricular activities (sport; 6). Five of the nine moderate-high

430 and moderate quality programs in which the authors evidenced life skills development and

431 transfer were delivered within the Community (Bean et al., 2016; Hodge et al., 2017;

432 Huysmans et al., 2019; Jacobs \& Wright, 2019; Waldron, 2009), two within Sport (Weiss et

433 al., 2013; Weiss et al., 2016), and two within Education (Goudas \& Giannoudis, 2010; Holt et

434 al., 2017). Overall, the life skills included within the 15 programs were: goal setting (12),

435 positive thinking (4), problem solving (5), communication (5), teamwork (7), health skills (3),

436 leadership (5), social support (2), self-management (3), media skills (1), reflection (1),

437 planning (2), seeking help (2), self-talk (3), social skills (1), relaxation (3), and values (1). Of

438 the nine moderate-high and moderate quality programs in which the authors evidenced life

439 skills development and transfer, the life skills included were: goal setting (7), positive thinking

440 (1), problem solving (3), communication (4), teamwork (6), health skills (3), leadership (5),

441 social support (2), self-management (4), media skills (1), reflection (1), planning (2), seeking

442 help (2), self-talk (3), social skills (1), relaxation (3), and values (1).

443 Program duration. Within the 15 included papers, programs ranged from one week to

444 two years, of which the number of sessions ranged between 3-57 sessions, and the duration of

445 the sessions ranged between 10-100 minutes. With regards to the nine moderate-high and

446 moderate quality papers in which the authors evidenced life skills development and transfer,

447 the life skills programs were delivered: over three weeks (Huysmans et al., 2019); four weeks

448 (Waldron, 2009); between 11 and 17 sessions (Goudas \& Giannoudis, 2010; Hodge et al., 
449 2017); over two years (Bean et al., 2016); and, over three months (Holt et al., 2013). The

450 authors of three of the moderate-high and moderate quality papers in which life skills

451 development and transfer were evidenced did not state the precise duration of the program

452 (Jacobs \& Wright, 2019; Weiss et al., 2013; Weiss et al., 2016). This may reflect the type of

453 community programs that they are, with no definitive start or end point. Catalano, Berglund,

454 Ryan, and Hawkins, (2004) suggested that for youth development programs to foster change,

455 they should run for a minimum of nine months or 10 sessions. Of the 15 papers included in the

456 review, only one program ran for the minimum duration of nine months (Bean et al., 2016).

457 Further, seven programs ran for the minimum duration of 10 sessions (e.g., Bean et al., 2015;

458 Goudas \& Giannoudis, 2008; 2010; Hodge et al., 2017; Holt et al., 2013; Huysmans et al.,

459 2019; Lee et al., 2017). Of the nine moderate and moderate-high quality papers in which the

460 authors evidenced life skills development and transfer, one program did not meet the duration

461 criteria (Waldron, 2009); three groups of authors did not state the duration of their programs

462 (Jacobs \& Wright, 2019; Weiss et al., 2013; Weiss et al., 2016), and five programs met the

463 minimum duration of 10 sessions and/or 9 months (Bean et al., 2016; Goudas \& Giannoudis,

464 2010; Hodge et al., 2017; Holt et al., 2013; Huysmans et al., 2019).

465 Individualization. Ten out of the 15 teams of authors referred to individualization of

466 the sport-based life skills program. Of the nine moderate and moderate-high quality papers in

467 which authors evidenced both life skills development and transfer, six made reference to

468 individualization within the program (i.e., Bean et al., 2016; Goudas \& Giannoudis, 2010;

469 Hodge et al., 2017; Holt et al., 2013; Huysmans et al., 2019; Jacobs \& Wright, 2019).

470 Individualization was illustrated through authors providing insight to the adaptations made to

471 SUPER for respective contexts (Goudas \& Giannoudis, 2010; Hodge et al., 2017); providing

472 participants with the choice of activities that would be carried out as part of the program (Bean

473 et al., 2016); creating bespoke core values (Jacobs \& Wright, 2019); or adapting the life skills

474 program based on the needs of the participants (Holt et al., 2013; Huysmans et al., 2019). 
Ongoing feedback. Six out of the 15 teams of authors indicated opportunities for ongoing feedback within the life skills programs. These six papers were also moderate-high

477 and moderate quality papers in which life skills development and transfer was evidenced. The

478 feedback strategies that these six adopted to evidence life skills development and transfer 479 included: debriefs to support progress (e.g., Bean et al., 2016; Jacobs \& Wright, 2019); coach

480 reinforcement to remind young people of the life skills that they were developing (e.g., Hodge

481 et al., 2017; Jacobs \& Wright, 2019; Weiss et al., 2013); ongoing feedback from parents

482 through reinforcement through setting homework (e.g., Goudas \& Giannoudis, 2010); and 483 reflective practice (Huysmans et al., 2019).

Pilot. Of the 15 included papers, only one group of authors provided information pertaining to implementing pilot versions of the sport-based life skills program. This paper was of moderate quality and one in which the authors evidenced life skills development and

487 transfer. Specifically, Holt et al. (2013) conducted an action research based study whereby they 488 used data collected from the first phase of the study to influence changes made to the second 489 phase of the study.

Intervention fidelity. Due to the integral role coaches play in the development of life

491 skills in young people and the lack of formal training provided to those delivering youth sport 492 programs (Petitpas et al., 2005), we specifically focused on coach training as an indicator of 493 intervention fidelity. Only four out of the 15 groups of authors referred to any form of coach 494 training. Of the nine moderate-high and moderate quality papers in which the authors 495 evidenced life skills development and transfer, three groups of authors referred to coach 496 training. Specifically, Weiss et al. (2013) outlined that coaches attended a two-day workshop, 497 whereby they were taught four 'deliberate teaching methods'. In addition, Jacobs and Wright 498 (2019) made reference to 'facilitators' engaging in annual coach training through a national 499 youth development sport organization. Huysmans et al. (2019) highlighted that coaches 500 attended three days of training through a train-the-trainer approach. Whilst insight is given into 
501 the teaching methods covered in the workshop, little insight is given into the detailed content 502 and delivery of the workshop.

\section{Quality of evaluation of sport-based life skills programs.}

\section{Sampling process}

Sample size. Of the 15 studies, sample sizes ranged between six and 564. Samples

ranged between six and 145 for the qualitative studies, between 72 to 564 for the quantitative studies, and between 15 and 36 for the mixed method studies. For the nine moderate-high and

508 moderate quality papers in which the authors evidenced life skills development and transfer

509 sample sizes ranged from 8-145 for the qualitative papers, 192-564 in the quantitative paper,

510 and 36 within the mixed method study.

Participants. We extracted data related to the participants included within each of the

51215 life skills programs. Participants were both male and female, aged between seven and 18

513 years old. In the nine moderate-high and moderate quality papers in which authors evidenced

514 both life skills development and transfer, two groups of authors used only female participants

515 between 11 and 16 years old (Bean et al., 2015; Waldron, 2009), and in the remaining seven

516 papers, male and female participants between 11 and 17 years old were included.

\section{Data Analysis}

Domain and methods. We extracted the domains (i.e., qualitative or quantitative) and

519 the methods that authors used to evaluate each of the 15 life skills programs. Authors adopted a

520 qualitative approach and used methods such as interviews or focus groups in ten papers and

521 adopted a quantitative approach and used methods such as questionnaires in the seven papers

522 (figures inclusive of both mixed method studies). Of the nine moderate-high and moderate

523 quality papers in which the authors evidenced life skills development and transfer, one team of

524 authors (Weiss et al., 2016) used quantitative methods, seven teams of authors used qualitative

525 methods (Bean et al., 2016; Goudas \& Giannoudis, 2010; Hodge et al., 2017; Holt et al., 2013; 
526 Jacobs \& Wright, 2019; Waldron, 2009; Weiss et al., 2013), and one team of authors used 527 mixed methods (Huysmans et al., 2019).

$528 \quad$ Frequency of evaluation. Of the 15 papers, authors conducted evaluations across four

529 time points: pre-intervention (6); during the intervention (4); post-intervention (14); and during

530 a follow-up period (5). In four of the nine moderate-high and moderate quality papers in which

531 the authors evidenced life skills development and transfer, data was collated post-intervention

532 (Bean et al., 2016; Holt et al., 2013; Waldron, 2009; Weiss et al., 2013). Two sets of authors of

533 the nine moderate-high and moderate quality papers collated data during the intervention and

534 post-intervention (Goudas \& Giannoudis, 2010; Jacobs \& Wright, 2019); one set of authors

535 collated data during the intervention and after a follow up period (Hodge et al., 2017); one set

536 of authors collected data pre intervention, post intervention and after a follow up period

537 (Huysmans et al., 2019); and another collated data during the intervention, post-intervention,

538 and after a follow-up period (Weiss et al., 2016).

539 Appropriate measures. We extracted data relating to the tools that authors used to

540 measure life skills development and/or transfer. Specifically, of the 15 papers included in the

541 review there were 15 different scales used to assess program effectiveness and, therefore, life

542 skills development and/or transfer (see Table 4). Of the nine moderate-high and moderate

543 quality papers in which the authors evidenced life skills development and transfer, one group

544 of authors used a valid measure to evaluate life skills development (Huysmans et al., 2019).

545 Further, of the nine moderate-high and moderate quality papers in which authors evidenced life

546 skills development and transfer, only one group of authors used a valid measure specifically

547 designed to evaluate life skills transfer, the Life Skills Transfer Scale (LSTS; Weiss, Bolter, \&

548 Kipp, 2014). Of the 15 papers included in the review, the authors of nine papers relied solely

549 on self-report data, whilst the authors of six papers also included parent, coach, and/or

550 facilitator perspectives of life skills development. Each of the authors of the nine moderate-

551 high and moderate quality papers in which life skills development and transfer collected self- 
552 report data, with the authors of five papers relying solely on self-report data. Authors of two of

553 the moderate quality papers also considered parent responses (Hodge et al., 2017; Weiss et al.,

554 2013), one group of authors considered coach responses to assess life skills development and

555 transfer (Weiss et al., 2013), one group of authors also considered teacher responses to life

556 skills development and transfer (Holt et al., 2013), and one group of authors considered both

557 coach and teacher responses to life skills development and transfer (Huysmans et al., 2019).

$558 \quad$ Comparable groups

Control group. Authors of only five of the 15 papers within this review included a

560 control group. Of these, only two were of moderate quality and evidenced life skills

561 development and transfer (Waldron, 2009; Weiss et al., 2016).

\section{Discussion}

Through this systematic review, our aim was to assess the quality of design and

564 evaluation methods of sport-based life skills programs in order to better understand the quality

565 of existing life skills research, and to influence the quality of future research in the area of life

566 skills development through sport. In doing this, we hoped to encourage researchers and

567 practitioners to consider and/or improve the quality of the life skills program design and the

568 methodological quality of the evaluations they conduct. As a result of considering quality,

569 researchers and practitioners can assess the strength of their claims of intervention

570 effectiveness and, thus, provide more credible findings. Fifteen papers met the inclusion

571 criteria on which we conducted two quality assessment exercises. As a result of combining

572 both design and evaluation quality, we determined three papers as moderate-high quality, 11

573 papers as moderate quality, and one paper as low quality. We then considered which of these

574 studies evidenced life skills development and transfer. Those included in this analysis were the

575 three moderate-high quality, six of the 11 moderate quality, and the one low quality paper.

576 Whilst the number of papers in the moderate quality and above category reflects an increase in

577 quality compared to the "weak" quality inferred by Whitley et al. (2019a; 2019b), it is 
578 important to note that the quality score within our study is an indication of the quality of both

579 design and evaluation methods. Further, of the 15 papers included in this review, only three

580 were of moderate-high quality. As such, claims of effectiveness for those papers whereby

581 quality is lacking should be interpreted with caution. Through a rigorous process of data

582 extraction and analysis, synthesized within a narrative description, we have provided a

583 descriptive overview of the characteristics of design and evaluation quality for moderate-high

584 and moderate quality papers in which life skills were proposed to be developed and transferred.

585 In this section we provide a discussion of these characteristics and then offer recommendations

586 on how researchers and practitioners can increase the design quality of life skills program and

587 the evaluation methods used.

588 Characteristics of Design Quality

589 From our synthesis, we observed that for the moderate-high and moderate quality

590 programs whereby life skills were developed and transferred, the program goals were clear and

591 life skills activities were embedded within the programs, illustrating a focused intervention.

592 Further, supporting the work of Jones and Lavallee (2009), young people believed that the life

593 skills included in the programs were important, and relatable to external contexts. Researchers

594 of the moderate and moderate-high quality programs in which authors evidenced life skills

595 development and transfer provided program descriptions, in which the following life skills

596 were included: communication, goal setting, teamwork, relaxation, self-talk, seeking help,

597 leadership, planning, self-management, health, social support, reflection, media skills, social

598 skills, positive thinking, problem solving, and values. By collating these life skills, we have

599 provided researchers and practitioners with a list of skills (derived from the moderate and

600 moderate-high quality peer reviewed papers included within this review in which authors

601 evidenced life skills development and life skills transfer) that are deemed valuable to the

602 functional development of young people. We have also found support for Catalano et al.'s

603 (2004) findings that effective youth development programs should be delivered for a minimum 
604 of 10 sessions or 9 months to facilitate behavior change. Indeed, of the nine moderate-high and 605 moderate quality papers whereby life skills development and transfer were evidenced, four 606 groups of authors specifically stated that their respective programs ran for at least 10 sessions.

607 Further, one group of authors stated their program ran for a minimum of nine months and 608 specifically used Catalano's recommendations as a guide. There were a number of design characteristics that were not demonstrated, which

610 affected the quality of the research. Indeed, by failing to evidence these design characteristics,

611 the overall quality score for program design was lower than what it would have been should

612 these characteristics have been evidenced. First, only one of the nine teams of authors of the

613 moderate-high or moderate life skills programs in which the authors evidenced life skills

614 development and transfer presented information pertaining to a pilot intervention (i.e., Holt et

615 al., 2013). Pilot interventions are important indicators of quality as they encourage researchers

616 to review program content, evaluation methods against the desired program aims, and make

617 necessary changes to ensure that the program is addressing the reported aims (McBride, 2016).

618 Second, with the exception of three teams of researchers, authors provided no insight into the

619 training offered to those delivering the life skills programs. Whilst we acknowledge that

620 facilitator training is not the only indicator of program fidelity, insight into facilitator training

621 is essential to support claims of effectiveness. Without this information it is unclear as to

622 whether the facilitator delivering the program had the appropriate knowledge and

623 understanding to deliver the program effectively. Researchers have also noted that facilitator

624 training is important as it can help coaches to develop an awareness of their role in facilitating

625 life skills in young people, and the strategies they can use to deliver life skills development and 626 transfer (Camiré, Kendellen, Rathwell, \& Charbonneau, 2018). Third, and similar to the low 627 numbers reported within Holt et al. (2017) and Whitley et al.'s (2019b) reviews, only five life 628 skills programs were theoretically underpinned. By utilizing theory to underpin their work, 629 researchers may identify and then test hypotheses that help improve understanding on the 
630 mechanisms that influence behavior. Such improved understanding may also help inform what

631 content and strategies researchers/practitioners should include in programs to better facilitate

632 life skills development and transfer (Prestwich et al., 2015). Our findings support Whitley et

633 al.'s (2019b) call for researchers to begin to test intervention theories as opposed to

634 intervention outcomes in order to identify the conditions and mechanisms that explain life

635 skills development outcomes. Last, we also observed a lack of involvement from parents in the

636 delivery and evaluation of life skills programs. Whilst researchers within the field of life skills

637 development have focused on the role of the coach in delivering sport-based life skills

638 programs (Camiré et al., 2012), very few researchers have explored the role of parents in sport-

639 based life skills programs (e.g., Hodge et al., 2017). The role of parents is important as

640 researchers have highlighted that the facilitation of life skills development in young people is

641 the collaborative role of parents, coaches, and significant others such as teachers (Bowley,

642 Cropley, Neil, Hanton, \& Mitchell, 2018), as all these collaborators may have an influence on 643 young people across many contexts.

\section{Characteristics of Evaluation Quality}

In the moderate-high and moderate quality papers in which authors evidenced

646 development and transfer of life skills, there were aspects of the evaluation methods that were

647 relatively consistent (e.g., sampling strategy [sample size and participants]; data analysis [e.g.,

648 domain, methods]; and appropriate measure [e.g., self-report data]). However, there were also

649 notable differences, and missing information in relation to the evaluation methods (e.g., data

650 analysis [frequency of evaluation]; appropriate measures [e.g., measuring life skills; multiple

651 sources]; and comparable groups [e.g., use of control groups]; researcher philosophy).

652 Specifically, researchers predominantly collated data post intervention, most likely due to the

653 nature of the research (i.e., qualitative). In that sense, there appears to be an over reliance on

654 qualitative research, potentially due to the lack of validated sport-specific measures that were

655 available to researchers at the time of publishing, an issue first identified by Gould and Carson 
656 in their review in 2008. In addition, there also appears to be an over-reliance on self-report

657 data, which may be contaminated by such reliability related issues as memory recall and social

658 desirability. Only two of the nine moderate-high and moderate quality papers in which the

659 authors evidenced life skills development and transfer included a control group, which enabled

660 them to infer that young people developed and transferred life skills as a specific result of

661 participating in the life skills program. Thus, these researchers were able to evidence a causal

662 relationship between life skills development and the life skills program. Further, researchers

663 failed to describe the demographics of groups, and illustrate how they accounted for any

664 differences between groups.

665 Future Research Recommendations

We recommend that those designing and evaluating life skills programs take steps

667 towards ensuring their research is of high quality. We reported only three papers as moderate-

668 high quality. From a design perspective, researchers wishing to publish a high-quality paper

669 should ensure that they provide a detailed description of the life skills intervention alongside

670 providing a clear program focus. Such a description would include providing insight into the

671 theory used to underpin the program, the duration of the program, and the structure of the life

672 skills program. Further, authors and/or practitioners should present the steps they took to

673 individualize the life skills program, and if and how ongoing feedback was integrated within

674 the program. Researchers should look to pilot their programs and share with readers the effects

675 of the pilot intervention. Lastly, it is important that researchers who want to evidence high

676 quality papers provide the reader with insight into life skills program fidelity. Whilst there are

677 a number of indicators of program fidelity, we have identified facilitator training as an

678 important avenue to enhance quality. That is, researchers should provide information about the

679 training that facilitators of life skills programs undergo prior to delivering the programs. 
682 program effects. Furthermore, researchers should utilize the quality assessment criteria (as

683 reported in this paper) to guide the development and evaluation of life skills programs.

684 Specifically, those adopting qualitative approaches should, at minimum, "identify their

685 disciplinary affiliation, what brought them to the question, and the assumptions they make

686 about the topic of interest" (Caelli, Ray, \& Mill, 2003, p. 5). This supports Whitley et al.'s

687 (2019a; 2019b) suggestion that researchers must consider philosophical, theoretical,

688 methodological, and analytical perspectives. In addition, those adopting quantitative

689 approaches should consider presenting information relating to complete outcome data,

690 including withdrawal/dropout. By illustrating this information, researchers may reinforce the

691 strength of the methodological design and administration they have engaged with, and as such,

692 the results of the study can be better generalized.

\section{Limitations}

When assessing the quality of studies, we acknowledge that there is a risk of evaluating

695 too harshly, as the researchers whose studies we are evaluating may not have had the space

696 (page limit) to disclose all relevant information. Further, when designing sport-based life skills

697 programs, they may have been governed by external organizations who can restrict the scope

698 of what is implemented. Given that the assessment of the quality of the design and evaluation

699 methods adopted by researchers relies on sufficient information being provided, the results of

700 our study should be considered with potential restrictions in mind. In addition, whilst we

701 identified six databases that we felt were relevant and would provide the best opportunity for

702 detecting relevant studies, it is important to note that it is difficult to identify all relevant

703 studies. In order to minimize the risk of not including appropriate studies, we enlisted the

704 support of the institution librarian to support with the development of the search strategy,

705 included a search for known authors in the field, and hand-searched the reference list of

706 relevant review papers and all included papers. Whilst these strategies were put in place to

707 ensure that we did not miss any papers, there is always a risk of eligible papers being missed. 
708 Indeed, we did not hand search the reference list of every single published review paper related

709 to positive youth development and/or life skills. As such, relevant research papers may have

710 been missed. Finally, we acknowledge that when designing and evaluating any intervention

711 program there are numerous difficulties that researchers may face that may impact the

712 evaluation methods adopted. For example, researchers' access to participants and/or the

713 willingness of participants to engage fully in the research may influence how the intervention

714 is designed and then delivered, and how it is evaluated throughout the program. In line with

715 our recommendations, it is, therefore, important that researchers provide sufficient information

716 related to the design and evaluation methods adopted, along with any restrictions and issues

717 faced, to help readers make their own decisions about researcher statements of quality and

718 intervention effectiveness.

\section{Applied Implications}

Schinke et al. (2020) recently identified a lack of rigor in relation to intervention design

721 within the Sport Psychology domain. Schinke et al. also made reference to a lack of specific,

722 high quality interventions within the field, highlighting that often high-quality research is

723 perceived to be difficult to conduct. Throughout this review, we have made practice-related

724 recommendations to researchers and practitioners proposing ways in which they can develop

725 high quality program designs and evaluations. Indeed, researchers and practitioners can draw

726 upon the quality guidelines outlined in the QATID to design high quality life skills

727 interventions. Specifically, researchers/practitioners should use frameworks, such as the

728 BNT/LDI (Hodge et al., 2012), to underpin the design of life skills programs in order to

729 identify how and why specific outcomes of life skills programs arise (Whitley et al., 2019b). In

730 addition, researchers/practitioners should ensure that life skills programs meet the minimum

731 duration recommendations for behavior change of 9 months or 10 sessions (Catalano et al.,

732 2004). Researchers/practitioners should conduct and evaluate pilot interventions whereby they

733 assess the content and delivery methods of the program and make changes if necessary. 
734 Finally, researchers/practitioners should consider how they will attempt to ensure programs are

735 delivered as intended. We recommend that researchers/practitioners provide training for those

736 delivering life skills programs to facilitate program fidelity and increase the quality of the life

737 skills program. By using an intervention design-related quality assessment tool when designing

738 sport-based life skills programs, researchers may be better able to validate subsequent claims

739 of program effectiveness. Additionally, researchers and those practitioners wishing to assess

740 the effectiveness of sport-based life skills programs must ensure they conduct quality

741 evaluations, considering: (a) sampling procedures; (b) data analysis processes; (c)

742 appropriateness of measures to evaluate life skills development; (d) inclusion of control

743 groups; and (e) the role of the researcher in the context. These indicators are important to

744 increase the quality in design and evaluation of sport-based life skills programs and should be

745 used by researchers, practitioners, academics and reviewers in their development and

746 assessment of papers to ensure that the issues relating to quality recently outlined by Schinke et

747 al. (2020) are addressed.

\section{Conclusion}

749 We have conducted the first systematic review that has explored the quality of sport750 based life skills development programs. Whilst it was difficult to compare these sport-based 751 programs due to the significant variations in program design and evaluation methods, the 752 present review provides insight into some important characteristics that influence the quality of 753 sport-based life skills programs. From a practical application perspective, we highlight that 754 these quality guidelines should be used by researchers and practitioners when designing and 755 evaluating future sport-based life skills programs. 


\section{References}

Bean, C., Forneris, T., \& Fortier, M. (2015). Girls just wanna have fun: Understanding perceptions of effective strategies and outcomes in a female youth-driven physical activitybased life skills programme. Journal of Sport for Development, 3, 28-40.

Bean, C., Kendellen, K., \& Forneris, T. (2016). Moving beyond the gym: Exploring life skill transfer within a female physical activity-based life skills program. Journal of Applied Sport Psychology, 28, 274-290.

Bean, C., Krammers, S., Forneris, T., \& Camiré, M. (2018). The implicit/explicit continuum of life skills development and transfer. Quest, 70, 1-15.

Bowley, C., Cropley, B., Neil, R., Hanton, S., \& Mitchell, I. (2018). A life skills development programme for youth football coaches: Programme development and preliminary evaluation. Sport \& Exercise Psychology Review, 14, 3-22.

Boyatzis, R. (1998). Transforming qualitative information: Thematic analysis and code development. Thousand Oaks, London: SAGE Publications

Braun, V. \& Clarke, V. (2006) Using thematic analysis in psychology. Qualitative Research in Psychology, 3, 77-101.

Brunelle, J., Danish, S., \& Forneris, T. (2007). The impact of a sport-based life skills program on adolescent prosocial values. Applied Developmental Science, 11, 43-55.

Caelli, K., Ray, L., \& Mill, J. (2003). 'Clear as mud': Toward greater clarity in generic qualitative research. International Institute for Qualitative Methodology, 2, 1-13.

Camiré, M., Trudel, P., \& Forneris, T. (2012). Coaching and transferring life skills: Philosophies and strategies used by model high school coaches. The Sport Psychologist, 26, 243-260.

Camiré, M., Kendellen, K., Rathwell, S., \& Charbonneau, E. (2018). Evaluation of the pilot implementation of the coaching for life skills program. International Sport Coaching Journal, 5, 227-236. 
783 Catalano, R., Berglund, M., Ryan, J., \& Hawkins, J. (2004). Positive youth development in the 784 United States: Research findings on evaluations of positive youth development programs. 785 The Annals of the American Academy, 591, 98-124.

786 Danish, S. J. (2002). Teaching life skills through sport. In M. Gatz, M. Messner \& S. Ball787 Rokeach (Eds.), Paradoxes of youth and sport (pp. 49-60). Albany, NY: State University of $788 \quad$ New York Press.

789 Danish, S. J., Petitpas, A., \& Hale, B. (1993). Life development intervention for athlete's life $790 \quad$ skills through sports. The Counseling Psychologist, 21, 352-385.

791 Danish, S., Forneris, T., Hodge, K., \& Heke, I. (2004). Enhancing youth development through 792 sport. World Leisure Journal, 46, 38-49.

793 Danish, S. J., Mash, J., Howard, C., Curl, S., Meyer, A., \& Owens, S. (1992a). Going for the 794 goal leader manual. Richmond, VA: Virginia Commonwealth University.

795 Davies, P., Walker, A., \& Grimshaw, J. (2010). A systematic review of the use of theory in the 796 design of guideline dissemination and implementation strategies and interpretations of the 797 results of rigorous evaluations. Implementation Science, 5, 1-6.

798 Fraser-Thomas, J., \& Côté, J. (2009). Understanding adolescents’ positive and negative 799 developmental experiences in sport. The Sport Psychologist, 23, 3-23.

800 Goudas, M., \& Giannoudis, G. (2008). A team-sports-based life-skills program in a physical $801 \quad$ education context. Learning and Instruction, 18, 528-536.

802 Goudas, M., \& Giannoudis, G. (2010). A qualitative evaluation of a life-skills program in a 803 physical education context. Hellenic Journal of Psychology, 7, 315-334.

804 Goudas, M., Dermitzaki, I., Leondari, A., \& Danish, S. (2006). The effectiveness of teaching a 805 life skills program in a physical education context. European Journal of Psychology of $806 \quad$ Education, 21, 429-438.

807 Gould, D., \& Carson, S. (2008). Life skills development through sport: Current status and 808 future directions. International Review of Sport and Exercise Psychology, 1, 58-78. 
Hellison, D. (1995). Teaching responsibility through physical activity. Champaign, IL: Human Kinetics.

Hermens, N., Super, S., Verkooijen, K., \& Koelen, M. (2017). A systematic review of life kill development through sports programs serving socially vulnerable youth. Research Quarterly for Exercise \& Sport, 88, 408-424.

814 Higgins, J., \& Green, S. (2011). Cochrane handbook for systematic reviews of interventions, Version 5.1.0. The Cochrane Collaboration, available from: www.cochrane-handbook.org

Hodge, K., Danish, S. J., \& Martin, J. (2012). Developing a conceptual framework for life skills interventions. Counselling Psychologist, 41, 1-28. Positive youth development outcomes of a sport-based life skills program. Journal of Park and Recreation, 35, 34-50.

Holt, N. L., McHugh, T., Tink, L., Kingsley, B., Coppola, A., Neely, K., \& McDonald, R. (2013). Developing sport-based after-school programmes using a participatory action research approach. Qualitative Research in Sport, Exercise \& Health, 5, 332-355. grounded theory of positive youth development through sport based on results from a qualitative meta-study. International Review of Sport \& Exercise Psychology, 10, 1-49. first": An exploration of the teaching personal and social responsibility model to youth development in Eswatini. Journal of Sport for Development, 7, 15-32. public health interventions. Health Promotion International, 20, 367-374.

832 Jacobs, J., \& Wright, P. (2019, online). Thinking about the transfer of life skills: Reflections from youth in a community-based sport programme in an underserved urban setting. 
835

Jones, M. I., \& Lavelle, D. (2009). Exploring the life skills needs of British adolescent athletes. Psychology of Sport and Exercise, 10, 159-167.

Jones, G., Edwards, M., Bocarro, J., Bunds, W., \& Smith, J. (2017). An integrative review of sport-based youth development literature. Sport in Society, 20, 161-179.

Kendellen, K., \& Camiré, M. (2017) Examining the life skill development and transfer experiences of former high school athletes. International Journal of Sport and Exercise Psychology, 15, 395-408.

Kmet, L., Lee, R., \& Cook, L. (2004). Standard quality assessment criteria for evaluating primary research papers from a variety of fields. HTA Initiative, 13, 1-20.

Lee, O., Park, M., Jang, K., \& Park, Y. (2017). Life lessons after classes: Investigating the influence of an afterschool sport on adolescents' life skills development. International Journal of Qualitative Studies on Health and Well-Being, 12, 1-10.

Mahoney, J. (2000). School extracurricular activity participation as a moderator in the development of antisocial patterns. Child Development, 71, 502-516.

Mahoney, J., Eccles, J., \& Larson, R. (2004). Processes of adjustment in organized out of school activities: Opportunities and risks. New Directions for Youth Development, 101, $115-144$.

McBride, N. (2016). Intervention research: A practical guide for developing evidence-based school prevention programmes. Singapore: Springer.

Moher, D., Liberati, A., Tetzlaff, J., Altman, D., \& Group, T. (2009). Preferred reporting items for systematic reviews and meta-analyses: The PRISMA statement. Annual of Internal Medicine, 151, 264-269.

Mullen, P., Green, L., \& Persinger, G. (1985). Clinical trials of patient education for chronic conditions: A comparative meta-analysis of intervention types. Preventative Medicine, 14, 753-781. 
860 Pace, R., Pluye, P., Bartlett, G, Macaulay, A., Salsberg, J., Jagosh, J., \& Seller, R. (2012).

861 Testing the reliability and efficiency of the pilot mixed methods appraisal tool (MMAT) for 862 systematic mixed studies review. International Journal of Nursing Studies, 49, 47-53.

863 Papacharisis, V., Goudas, M., Danish, S. J., \& Theodorakis, Y. (2005). The effectiveness of 864 teaching a life skills program in a sport context. Journal of Applied Sport Psychology, 17, $865 \quad 247-254$

866 Pawson, R., Boaz, A., Grayson, L., Long, A., \& Barnes, C. (2003). Types and quality of $867 \quad$ knowledge in social care knowledge review 3, SCIE: London UK.

868 Petitpas, A., Cornelius, A., Van Raalte, J., \& Jones, T. (2005). A framework for planning youth 869 sport programs that foster psychosocial development. The Sport Psychologist, 19, 63-80.

870 Pierce, S., Gould, D., \& Camiré, M. (2016). Definition and model of life skills transfer.

871 International Review of Sport and Exercise Psychology, 10, 186-211.

872 Pluye, P., Robert, E., Cargo, M., Bartlett, G., O’Cathian, A., Griffiths, F., Boardman, F., 873 Gagnon, M., \& Rousseau, M. (2011). Proposal: A mixed methods tool for systematic mixed 874 studies reviews. Available online at: http://mixedmethodsappraisaltoolpublic.pbworks.com (Accessed August 2017)

Prestwich, A., Webb, T., \& Conner, M. (2015). Using theory to develop and test interventions to promote changes in health behavior: Evidence, issues, and recommendations. Current Opinion in Psychology, 5, 1-5.

Rigoni, P., Belem, I., \& Viera, L. (2017). Systematic review on the impact of sport on the positive youth development of high performance athletes. Journal of Physical Education, $28,1-13$.

882 Robertson, E., Wakefield, C., Signorelli, C., Cohn, R., Patenaude, A., Foster, C., Pettit, T., \& 883 Fardell, J. (2018). Strategies to facilitate shared decision-making about pediatric oncology clinical trial enrolment: A systematic review. Patient Education and Counseling, 101, 11571174. 
886

Schinke, R., Mellalieu, S. D., Ntoumanis, N., Kavussanu, M., Standage, M., Strauss, B., \& Papaioannou, A. (2020, online). Getting published: Suggestions and strategies from editors of sport and exercise psychology journals. Journal of Applied Sport Psychology.

Schulz, K., Altman, D., \& Moher, D. (2010). CONSORT 2010 statement: Updated guidelines for reporting parallel group randomised trials. British Medical Journal, 340, 697-702.

Turnnidge, J., Côté, J., \& Hancock, D. (2014). Positive youth development form sport to life: Explicit or implicit transfer? QUEST, 66, 203-217.

Waldron, J. (2009). Development of life skills and involvement in the girls on track program. Women in Sport and Physical Activity, 18, 60-73.

Weiss, M., Bolter, N., \& Kipp, L. (2016). Evaluation of the first tee in promoting positive youth development: Group comparisons and longitudinal trends. Research Quarterly for Exercise and Sport, 87, 271-283.

Weiss, M., Stuntz, C., Bhalla, J., Bolter, N., \& Price, M. (2013). More than a game: Impact of the first tee life skills program on positive youth development: Project introduction and year 1 findings. Qualitative Research in Sport, Exercise and Health, 5, 214-24.

Whitley, M., Massey, W., Camiré, M., Boutet, M., \& Borbee, A. (2019a). Sport-based youth development interventions in the united states: A systematic review. BMC Public Health, $19,1-20$

Whitley, M., Massey, W., Camiré, M., Blom, L.C., Chawansky, M., Forde, S. ... Darnell, S. (2019b). A systematic review of sport for development interventions across six global cities. Sport Management Review, 22, 181-193.

Wholey, J., Hatry, H., \& Newcomer, K. (2015). Handbook of practical program evaluation. Jossey-Bass: San Francisco 

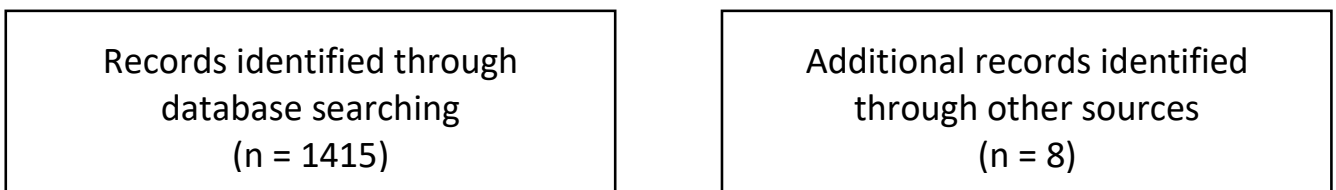

$$
(n=1415)
$$

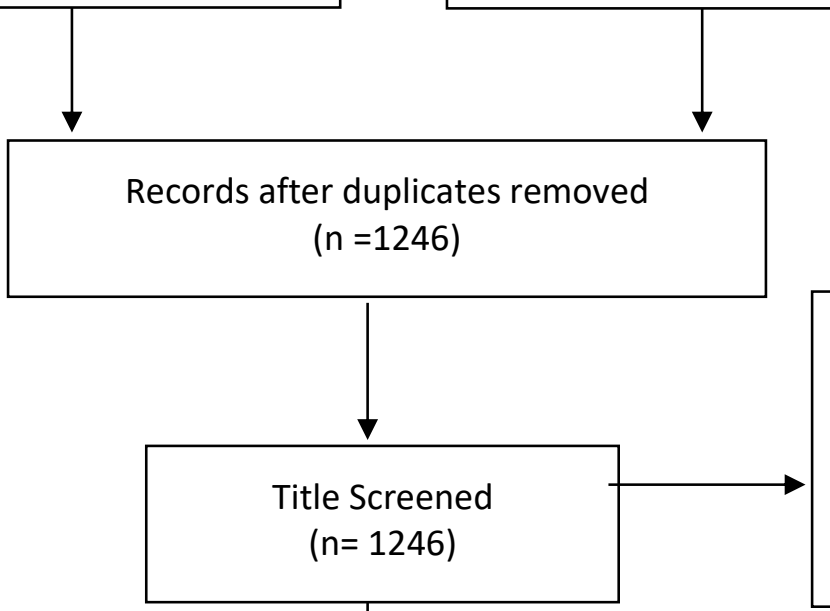

Adult participants

- Book Chapter, Book Review,

- Life Skills not in title

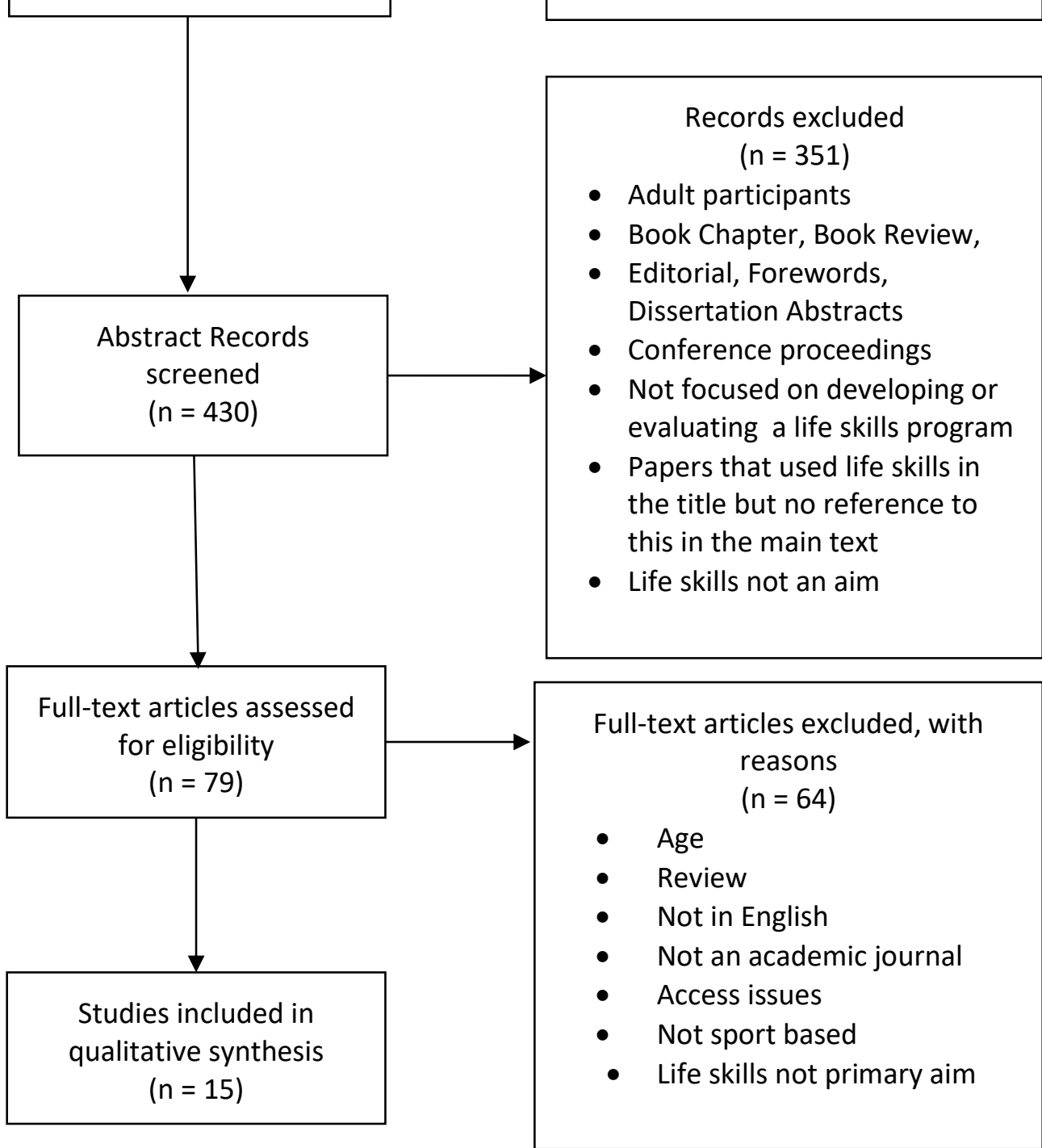

Figure 1: PRISMA Flow Diagram 
Table 1: Intervention Design Quality Assessment Scores

\begin{tabular}{|c|c|c|c|c|c|c|c|c|c|c|}
\hline Name & THEO & INTFOC & DET & DUR & INDIV & ONFEED & PILOT & FID & Overall Score & $\%$ \\
\hline Bean et al., (2015) & 1 & 2 & 1 & 2 & 1 & 0 & 0 & 1 & 8 & $50 \%$ \\
\hline Bean et al. (2016) & 1 & 2 & 1 & 2 & 1 & 2 & 0 & 0 & 9 & $56 \%$ \\
\hline Brunelle et al. (2007) & 0 & 2 & 1 & 0 & 0 & 0 & 0 & 0 & 3 & $19 \%$ \\
\hline Goudas et al. (2006) & 0 & 2 & 1 & 0 & 1 & 0 & 0 & 0 & 4 & $25 \%$ \\
\hline Goudas \& Giannoudis, (2008) & 0 & 2 & 1 & 2 & 1 & 1 & 0 & 0 & 7 & $44 \%$ \\
\hline Goudas \& Giannoudis, (2010) & 0 & 2 & 1 & 2 & 1 & 1 & 0 & 0 & 6 & $38 \%$ \\
\hline Hodge et al. (2017) & 0 & 2 & 1 & 2 & 1 & 1 & 0 & 0 & 7 & $44 \%$ \\
\hline Holt et al. (2013) & 0 & 1 & 1 & 2 & 1 & 1 & 0 & 0 & 7 & $44 \%$ \\
\hline Huysmans et al. (2019) & 2 & 2 & 1 & 2 & 2 & 1 & 0 & 1 & 11 & $69 \%$ \\
\hline Jacobs \& Wright (2019) & 0 & 2 & 1 & 1 & 1 & 2 & 0 & 1 & 8 & $50 \%$ \\
\hline Lee et al. (2017) & 0 & 2 & 0 & 2 & 0 & 0 & 0 & 1 & 5 & $31 \%$ \\
\hline Papacharisis et al. (2005) & 0 & 2 & 0 & 0 & 1 & 0 & 0 & 0 & 3 & $19 \%$ \\
\hline Waldron, (2009) & 0 & 2 & 1 & 0 & 0 & 0 & 0 & 0 & 3 & $19 \%$ \\
\hline Weiss et al. (2013) & 1 & 2 & 0 & 0 & 0 & 1 & 0 & 1 & 5 & $31 \%$ \\
\hline
\end{tabular}

Weiss et al. (2016)

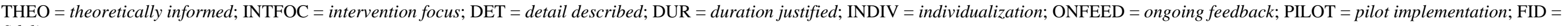
fidelity.

Table 2: Mixed Methods Appraisal Tool (MMAT; Pluye et al., 2011)

\begin{tabular}{|c|c|c|c|c|c|c|c|c|c|c|c|c|c|c|c|c|c|}
\hline & \multicolumn{4}{|c|}{ Qualitative } & \multicolumn{4}{|c|}{$\begin{array}{c}\text { Quantitative } \\
\text { Non-Randomized }\end{array}$} & \multicolumn{4}{|c|}{$\begin{array}{l}\text { Quantitative } \\
\text { Descriptive }\end{array}$} & \multicolumn{3}{|c|}{ Mixed Methods } & \multirow[t]{2}{*}{ Results } & \multirow[t]{2}{*}{ Combined \% } \\
\hline & 1 & 2 & 3 & 4 & 1 & 2 & 3 & 4 & 1 & 2 & 3 & 4 & 1 & 2 & 3 & & \\
\hline Bean et al. (2015) & $\checkmark$ & $\checkmark$ & $x$ & $x$ & & & & & $\checkmark$ & $x$ & $\checkmark$ & $\checkmark$ & $\checkmark$ & $\checkmark$ & $x$ & $50 \%$ & $50 \%$ \\
\hline Bean et al. (2016) & $\checkmark$ & $\checkmark$ & $\checkmark$ & $x$ & & & & & & & & & & & & $75 \%$ & $65.5 \%$ \\
\hline Brunelle et al. (2007) & & & & & & & & & $x$ & $x$ & $\checkmark$ & $\checkmark$ & & & & $50 \%$ & $34.5 \%$ \\
\hline Goudas et al. (2006) & & & & & $\checkmark$ & $\checkmark$ & $x$ & $x$ & & & & & & & & $50 \%$ & $37.5 \%$ \\
\hline Goudas \& Giannoudis, (2008) & & & & & $\checkmark$ & $\checkmark$ & $x$ & $x$ & & & & & & & & $50 \%$ & $47 \%$ \\
\hline Goudas \& Giannoudis, (2010) & $\checkmark$ & $\checkmark$ & $\checkmark$ & $x$ & & & & & & & & & & & & $75 \%$ & $56.5 \%$ \\
\hline Hodge et al. (2017) & $x$ & $\checkmark$ & $x$ & $x$ & & & & & & & & & & & & $25 \%$ & $34.5 \%$ \\
\hline Huysmans et al. (2019) & $\checkmark$ & $\checkmark$ & $\checkmark$ & $\checkmark$ & & & & & $x$ & $\checkmark$ & $\checkmark$ & $x$ & $x$ & $x$ & $x$ & $50 \%$ & $62.5 \%$ \\
\hline Jacobs \& Wright (2019) & $\checkmark$ & $\checkmark$ & $\checkmark$ & $\checkmark$ & & & & & & & & & & & & $100 \%$ & $75 \%$ \\
\hline Lee et al. (2017) & $x$ & $\checkmark$ & $x$ & $x$ & & & & & & & & & & & & $25 \%$ & $28 \%$ \\
\hline Papacharisis et al. (2005) & & & & & $\checkmark$ & $\checkmark$ & - & - & & & & & & & & $50 \%$ & $34.5 \%$ \\
\hline Waldron, (2009) & $\checkmark$ & $\checkmark$ & - & $x$ & & & & & & & & & & & & $50 \%$ & $34.5 \%$ \\
\hline Weiss et al. (2013) & $\checkmark$ & $\checkmark$ & $x$ & $x$ & & & & & & & & & & & & $50 \%$ & $40.5 \%$ \\
\hline Weiss et al. (2016) & & & & & $\checkmark$ & $\checkmark$ & $x$ & - & & & & & & & & $50 \%$ & $34.5 \%$ \\
\hline
\end{tabular}


Table 3: Characteristics of Design

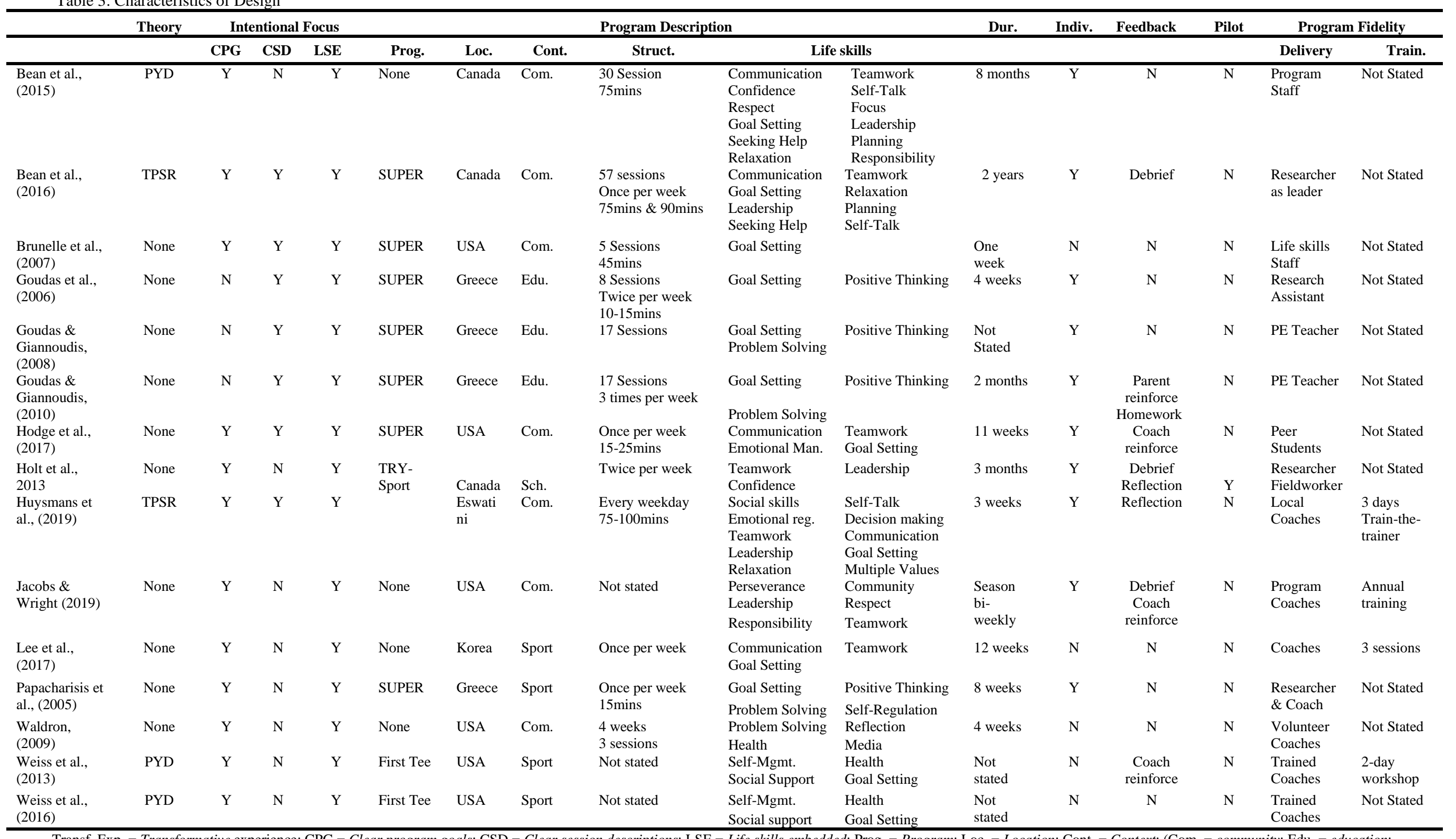

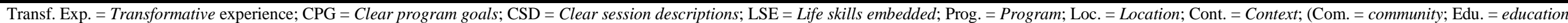
Sch. $=$ school $) ;$ Struct. $=$ Structure $;$ Dur. = Duration $;$ Indiv. = Individualization $;$ Feedback = Ongoing feedback $;$ Train. = Training for those delivering intervention. 
Table 4: Characteristics of Evaluation Method

\begin{tabular}{|c|c|c|c|c|c|c|c|c|c|c|}
\hline & \multicolumn{2}{|c|}{ Sampling } & \multirow[b]{2}{*}{ Domain } & \multicolumn{2}{|l|}{ Data Analysis } & \multicolumn{2}{|l|}{ Appropriate Measure } & \multirow[b]{2}{*}{ Self-Report } & \multirow{2}{*}{$\begin{array}{c}\begin{array}{c}\text { Comp. } \\
\text { groups }\end{array} \\
\text { Cont. } \\
\text { Group }\end{array}$} & \multirow[t]{2}{*}{ Outcome } \\
\hline & Sample Size & $\begin{array}{l}\text { Program } \\
\text { Participants }\end{array}$ & & Method & $\begin{array}{l}\text { Freq. of } \\
\text { Eval. }\end{array}$ & Instrument & $\begin{array}{l}\text { Valid } \\
\text { Meas. }\end{array}$ & & & \\
\hline Bean et al., (2015) & $\begin{array}{l}10 \text { Youth } \\
5 \text { Leaders }\end{array}$ & $\begin{array}{l}\text { Girls } \\
\text { Avg. Age } 11.75\end{array}$ & Mixed Method & $\begin{array}{l}\text { Interviews } \\
\text { Questionnaire }\end{array}$ & Post & $\begin{array}{l}\text { Semi-structured Interviews } \\
\text { Youth Experience Survey (YES) } 2.0\end{array}$ & $\mathrm{Y}$ & $\begin{array}{l}\text { Youth } \\
\text { Leaders }\end{array}$ & No & Development \\
\hline Bean et al. (2016) & 8 & $\begin{array}{l}\text { Girls } \\
\text { Age 11-16 }\end{array}$ & Qualitative & Interview & $\begin{array}{l}\text { During } \\
\text { Post }\end{array}$ & Semi-Structured & N/A & Youth & No & $\begin{array}{l}\text { Development \& } \\
\text { Transfer }\end{array}$ \\
\hline Brunelle et al. (2007) & 100 & $\begin{array}{l}\text { Boys \& Girls } \\
\text { Age } 13-17\end{array}$ & Quantitative & Questionnaire & $\begin{array}{l}\text { Pre/Post } \\
\text { Follow up }\end{array}$ & $\begin{array}{l}\text { SPRS, IRI, SIS, Goal Knowledge, Goal Self } \\
\text { Efficacy, Comm service }\end{array}$ & $\mathrm{Y}$ & Youth & No & $\begin{array}{l}\text { Partial } \\
\text { Development }\end{array}$ \\
\hline $\begin{array}{l}\text { Goudas \& Giannoudis } \\
\text { (2010) }\end{array}$ & 86 & $\begin{array}{l}\text { Boys \& Girls } \\
\text { Age 11-14 }\end{array}$ & Qualitative & $\begin{array}{l}\text { Interviews, Field } \\
\text { Notes Workbooks }\end{array}$ & Post & Semi-Structured & N/A & Youth & No & $\begin{array}{l}\text { Development \& } \\
\text { Transfer }\end{array}$ \\
\hline $\begin{array}{l}\text { Goudas \& Giannoudis } \\
(2008)\end{array}$ & 130 & Age 12-14 & Quantitative & Questionnaire & Pre/Post & $\begin{array}{l}\text { Knowledge Test, Self-belief of ability \& Sport } \\
\text { Skills test }\end{array}$ & Y & Youth & Yes & Development \\
\hline Goudas et al. (2006) & 73 & $\begin{array}{l}\text { Boys \& Girls } \\
\text { Avg. age } 12 \\
\end{array}$ & Quantitative & Questionnaire & $\begin{array}{l}\text { Pre/Post } \\
\text { Follow up }\end{array}$ & $\begin{array}{l}\text { Physical Fitness Test, Knowledge Test, Self- Belief } \\
\text { of ability }\end{array}$ & $\mathrm{Y}$ & Youth & Yes & $\begin{array}{l}\text { Partial } \\
\text { Development } \\
\end{array}$ \\
\hline Hodge et al. (2017) & 36 & $\begin{array}{l}\text { Boys \& Girls } \\
\text { Age } 7-15\end{array}$ & Qualitative & Interviews & $\begin{array}{l}\text { During } \\
\text { Follow up } \\
\end{array}$ & Semi-Structured & N/A & $\begin{array}{l}\text { Youth } \\
\text { Parents } \\
\end{array}$ & No & $\begin{array}{l}\text { Development \& } \\
\text { Transfer }\end{array}$ \\
\hline Holt et al. 2013 & $\begin{array}{l}\text { Study 1: } 28+2 \\
\text { Study } 2: 14+3\end{array}$ & $\begin{array}{l}\text { Boys \& Girls Age } \\
7-9\end{array}$ & Qualitative & Interviews & Post & Semi-structured & N/A & $\begin{array}{l}\text { Youth } \\
\text { Teachers }\end{array}$ & No & $\begin{array}{l}\text { Development \& } \\
\text { Transfer }\end{array}$ \\
\hline Huysmans et al., 2019 & $\begin{array}{l}33 \text { youth } \\
2 \text { coaches } \\
1 \text { Teacher }\end{array}$ & $\begin{array}{l}\text { Boys \& Girls } \\
\text { Age } 11-15\end{array}$ & Mixed Method & $\begin{array}{l}\text { Focus Groups } \\
\text { Questionnaire } \\
\text { Interview }\end{array}$ & $\begin{array}{l}\text { Pre/Post } \\
\text { Follow up }\end{array}$ & $\begin{array}{l}\text { Focus Groups, Interview } \\
\text { PSRQ, MSPSE } \\
\text { Learning quiz }\end{array}$ & Y & $\begin{array}{l}\text { Youth } \\
\text { Coaches } \\
\text { Teachers }\end{array}$ & No & $\begin{array}{l}\text { Development \& } \\
\text { Transfer }\end{array}$ \\
\hline Jacobs \& Wright (2019) & 11 & $\begin{array}{l}\text { Boys \& Girls } \\
\text { Age } 12-18\end{array}$ & Qualitative & $\begin{array}{l}\text { Focus Group } \\
\text { Interviews } \\
\text { Observations } \\
\text { Field journal }\end{array}$ & During Post & $\mathrm{N} / \mathrm{S}$ & N/A & Youth & No & $\begin{array}{l}\text { Development \& } \\
\text { Transfer }\end{array}$ \\
\hline Lee et al. (2017) & $\begin{array}{l}6 \\
2 \text { instructors } \\
\end{array}$ & $\begin{array}{l}\text { Boys \& Girls } \\
\text { Avg. age } 11.5 \\
\end{array}$ & Qualitative & Interviews & $\begin{array}{l}\text { Pre } \\
\text { Post }\end{array}$ & $\mathrm{N} / \mathrm{S}$ & N/A & $\begin{array}{l}\text { Youth } \\
\text { Facilitator } \\
\end{array}$ & No & $\begin{array}{l}\text { Development \& } \\
\text { Transfer }\end{array}$ \\
\hline Papacharisis et al. (2005) & 72 & $\begin{array}{l}\text { Boys \& Girls } \\
\text { Age } 10-12\end{array}$ & Quantitative & Questionnaire & $\begin{array}{l}\text { Pre } \\
\text { Post }\end{array}$ & $\begin{array}{l}\text { Knowledge Test, Self-belief of ability \& Sport } \\
\text { Skills test }\end{array}$ & $\mathrm{Y}$ & Youth & Yes & Development \\
\hline Waldron (2009) & 19 & $\begin{array}{l}\text { Girls } \\
\text { Age 11-13 }\end{array}$ & Qualitative & Interviews & Post & Semi-Structured & N/A & Youth & Yes & $\begin{array}{l}\text { Development \& } \\
\text { Transfer }\end{array}$ \\
\hline Weiss et al. (2013) & $\begin{array}{l}95 \text { youth } \\
26 \text { coaches } \\
24 \text { parents }\end{array}$ & $\begin{array}{l}\text { Boys \& Girls } \\
\text { Age } 11-17\end{array}$ & Qualitative & $\begin{array}{l}\text { Interviews } \\
\text { Focus Groups }\end{array}$ & Post & N.S & N/A & $\begin{array}{l}\text { Youth } \\
\text { Parents } \\
\text { Coaches }\end{array}$ & No & $\begin{array}{l}\text { Development \& } \\
\text { Transfer }\end{array}$ \\
\hline Weiss et al. (2016) & $\begin{array}{l}\text { Study 1: } 564 \\
\text { Study 2: } 192\end{array}$ & $\begin{array}{l}\text { Boys \& Girls } \\
\text { Age } 10-17\end{array}$ & Quantitative & Questionnaire & $\begin{array}{l}\text { During } \\
\text { Post } \\
\text { Follow up }\end{array}$ & $\begin{array}{l}\text { LSTS, SPP, SPPa, Character Dev. scale, SSE; } \\
\text { Preference for challenge scale }\end{array}$ & $\mathrm{Y}$ & Youth & Yes & Transfer \\
\hline
\end{tabular}

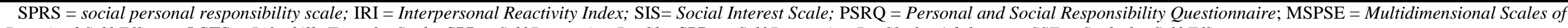

Perceived Self-Efficacy; LSTS = Life skills Transfer Scale; SPP = Self Perception Profile; SPPa = Self Perception Profile for Adolescent; SSE = Scale for Self-Efficacy. 